\title{
Determination of rare earth and refractory trace element abundances in early solar system objects by ion microprobe
}

\author{
S SAhiJPal ${ }^{1}$, K K MARhas ${ }^{2 *}$ and J N Goswami ${ }^{2}$ \\ ${ }^{1}$ Department of Physics, Panjab University, Chandigarh 160 014, India. \\ ${ }^{2}$ Physical Research Laboratory, Navrangpura, Ahmedabad 380 009, India. \\ *Present Address: Max-Planck Institut fur Chemie, Cosmochemistry Division, Mainz 55020, Germany.
}

\begin{abstract}
Experimental and analytical procedures devised for measurement of rare earth element (REE) abundances using a secondary ion mass spectrometer (ion microprobe) are described. This approach is more versatile than the conventional techniques such as neutron activation analysis and isotope dilution mass spectrometry by virtue of its high spatial resolution that allows determination of REE abundances in small domains (10-20 micron) within individual mineral phases. The ion microprobe measurements are performed at a low mass-resolving power adopting the energy-filtering technique (Zinner and Crozaz 1986) for removal and suppression of unresolved complex molecular interferences in the REE masses of interest. Synthetic standards are used for determining various instrument specific parameters needed in the data deconvolution procedure adopted for obtaining REE abundances. Results obtained from analysis of standards show that our ion microprobe may be used for determining REE abundances down to ppm range with uncertainties of $\sim 10$ to $15 \%$. Abundances of rare earth and several other refractory trace elements in a set of early solar system objects isolated from two primitive carbonaceous chondrites were determined using the procedures devised by us. The results suggest that some of these objects could be high temperature nebular condensates, while others are products of melting and recrystallization of precursor nebular solids in a high temperature environment.
\end{abstract}

\section{Introduction}

The rare earth elements (REE) or lanthanides, constitute a group of fourteen elements from Lanthanum to Lutetium, that are found in trace amounts in terrestrial and extraterrestrial samples (Boynton 1984; Henderson 1984). These elements show characteristic behaviour as a group during geochemical (e.g., igneous and metamorphic) processes. REE abundances in solids formed during igneous processes are determined by solid $/ \mathrm{melt}$ partitioning co-efficients that are related to the REE ionic size which decrease with increasing atomic number. However, in processes that involve gas/solid transformation (e.g., condensation or volatilization) the REE abundances in solid are primarily determined by the relative REE volatilities that are neither similar nor show any dependence on atomic number. The ability to distinguish between geochemical (e.g., igneous) and cosmochemical (e.g., condensation) processes based on REE abundances has proven to be extremely useful for understanding the physico-chemical processes involved in the formation of early solar system solids (see e.g., Boynton 1984, 1989; McPherson et al 1988).

Several analytical techniques such as neutron activation analysis and isotope dilution mass spectrometry are generally used for determining REE abundances in both terrestrial and extra-

Keywords. Rare earth element; ion microprobe; solar nebula; hibonite; carbonaceous chondrite. 
terrestrial samples. The neutron activation technique involves neutron irradiation of the sample followed by measurement of activity of specific radionuclides (instrumental neutron activation analysis, INAA), a nondestructive approach, or measurement of activity of chemically separated REE fractions (radiochemical neutron activation analysis, RNAA). Isotope dilution mass spectrometry also involves chemical separation of REE fractions. Both these techniques may be used to measure absolute REE abundances at ppm (parts per million) level with uncertainties of a few per cent. However, these methods yield "average" values of REE abundances in the analyzed sample and it is not possible to identify the dominant REE carrier amongst the various phases that may be present in it. This shortcoming and the need for chemical separation of REE make these techniques inappropriate for studying REE abundances in individual mineral phases within a phase assemblage or in microscopic domain within a given mineral phase. The secondary ion mass spectrometer, commonly known as the ion microprobe, that is capable of determining isotopic and elemental abundances in solids with spatial resolution of a few microns is ideally suited for this purpose and has been used extensively in recent years for determining REE abundances in microscopic extraterrestrial samples (Fahey et al 1987; Hinton et al 1988; Ireland et al 1988; Ireland 1990, Sahijpal et al 2000). It may be noted that the ion microprobe can also be used for rapid analysis of chemically separated REE from bulk samples based on the isotopic dilution approach (Allegre et al 1989). In this paper we describe the experimental and analytical procedures devised by us for measuring abundances of REE and several other refractory trace elements (RTE) using a Cameca ims-4f ion microprobe at the Physical Research Laboratory (PRL), Ahmedabad. Results obtained from studies of REE abundances in synthetic silicate standards and in a selected set of microscopic early solar system objects are presented. We also discuss the implications of the data for understanding the processes governing the formation of these early solar system objects.

\section{Determination of REE abundance by an ion microprobe}

\subsection{The basic approach}

The secondary ion mass spectrometer or the ion microprobe employs an energetic primary ion beam for sputtering secondary ions from a solid target. The sputtered secondary ions are accelerated, energy sorted and mass analyzed to obtain intensities of ions of different masses using suitable ion detection devices. The measured ion intensities at different masses reflect abundances of corresponding isotopes/elements in the sputtered target. Since the incident primary ion beam can be focused to a spot size down to a few microns, the ion microprobe is ideally suited to determine elemental/isotopic composition in microscopic domains within individual samples.

The major problem of routine determination of REE abundances by ion microprobe is that of resolving molecular and isobaric interferences at the REE masses of interest. These interferences could be simple elemental monoxides or complex molecular interferences. For example, if the analyzed phase contains calcium and phosphorous, the secondary ion signal at atomic mass 159, corresponding to the REE Terbium (Tb), will consist of contribution from ${ }^{159} \mathrm{~Tb}$ as well as from the complex molecular species $\left[{ }^{40} \mathrm{Ca}_{2}{ }^{31} \mathrm{P}^{16} \mathrm{O}_{3}\right]$ and another REE oxide $\left[{ }^{143} \mathrm{Nd}^{16} \mathrm{O}\right]$. In order to determine the abundance of $\mathrm{Tb}$, it is necessary to resolve the oxide and molecular interferences or devise methods to accurately estimate their magnitude by appropriate analytical procedures. In the case of $\mathrm{Tb}$, the mass-revolving power $(M / \Delta M)$ needed to resolve the interferences is $\sim 8,000$. Since the typical REE abundances are at ppm level, use of such high mass-resolving power will drastically reduce the ${ }^{159} \mathrm{~Tb}$ ion signal reaching the detector and a meaningful determination of $\mathrm{Tb}$ abundance will not be feasible. In fact for many other REEs, the mass-resolving power needed is even higher and beyond the limit of the ion microprobe.

\subsection{The "energy-filtering" technique}

The above problem can be circumvented by the "energy filtering" technique (see e.g., Zinner and Crozaz 1986; Fahey 1998) that enables elimination of interferences from complex molecular species (e.g., $\quad\left[{ }^{40} \mathrm{Ca}_{2}{ }^{31} \mathrm{P}^{16} \mathrm{O}_{3}\right]$ ) and significantly reduces the magnitude of monoxide interferences (e.g., $\left[{ }^{143} \mathrm{Nd}^{16} \mathrm{O}\right]$ ). The residual interferences from monoxide and other unresolved isobaric species are then corrected and REE abundances may be determined using suitable analytical approach for data deconvolution. We have accomplished this using a Cameca ims-4f ion microprobe at PRL; the procedural details are briefly described in the following sub-sections.

\subsection{Experimental and analytical procedures}

The measurements were carried out using a focused (spot-size $\sim 10$ to $20 \mu \mathrm{m})$ energetic $(17 \mathrm{keV}){ }^{16} \mathrm{O}^{-}$ 


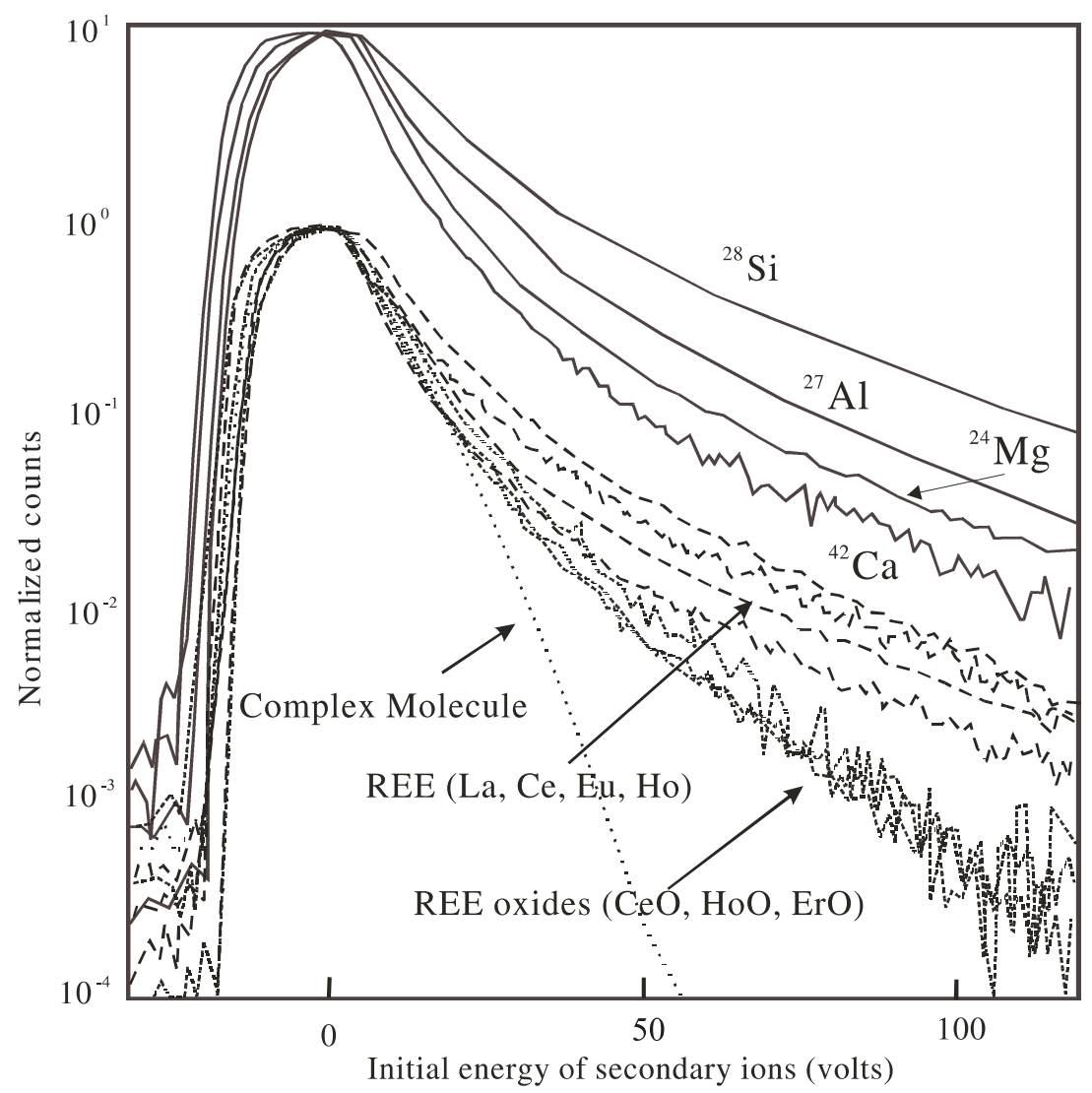

Figure 1. Normalized secondary ion energy spectra of major elements, REE and REE mono-oxides obtained from analysis of NIST silicate standard (Fahey 1998). Secondary ions within an energy band of $\sim 25$ volts were accepted during analysis. Major elements are normalized independently for clarity in data display.

primary ion beam with high intensity $(5-15 \mathrm{nA})$ at a low mass resolution $(M / \Delta M) \sim 300$ (wide open entrance and exit slits) to achieve maximum transmission of sputtered secondary ions. Positive secondary ions from the sample that was kept at a potential of $4.5 \mathrm{kV}$ were extracted using a grounded extraction plate. The extracted ions were energy filtered using an electrostatic analyzer and ions within a narrow energy band ( $\sim 25$ volts) were let into the mass (magnetic) analyzer. The ion intensities at the different masses of interest were determined using an electron multiplier operating in a pulse-counting mode. The sputtered secondary ions from the sample surface have a broad dispersion in their initial energies (up to $\sim 150 \mathrm{eV}$ ), with maximum intensity at low energies of a few electron volts. In figure 1, we show the normalized secondary ion energy spectra for various isotopes of major elements such as $\mathrm{Mg}, \mathrm{Al}, \mathrm{Si}, \mathrm{Ca}, \mathrm{REE}$ (La, $\mathrm{Ce}, \mathrm{Eu}, \mathrm{Ho}$ ) and REE monoxide (CeO, $\mathrm{HoO}, \mathrm{ErO})$ obtained from various synthetic glass standards under similar instrument operating conditions. Several important features that are readily evident in the data are: (i) intensities of REE monoxide ions $\left[(\mathrm{CeO})^{+},(\mathrm{HoO})^{+},(\mathrm{ErO})^{+}\right]$drop faster than the corresponding $\mathrm{REE}$ ions $\left(\mathrm{Ce}^{+}, \mathrm{Ho}^{+}, \mathrm{Er}^{+}\right)$as a function of their initial energy and for energies $\geq 70$ volts, intensities of REE monoxide ions are almost an order of magnitude lower than the corresponding REE ions; (ii) intensities of complex molecular ions drop even faster and for initial energies $>50$ volts their intensities are several orders of magnitude below that of the REE ions; (iii) the drop in intensity for the REE ions parallels that of the isotopes of major elements (e.g., ${ }^{28} \mathrm{Si},{ }^{27} \mathrm{Al},{ }^{24} \mathrm{Mg},{ }^{42} \mathrm{Ca}$ ) for initial energy $\geq 60$ volts. These features are basic ingredients of the "energyfiltering" technique in which the instrument is set up for analysis of secondary ions with initial energies $>60$ volts, thereby eliminating the complex molecular ion interferences and significantly suppressing the intensities of monoxide interferences relative to the REE ions. As noted earlier, the ion microprobe is initially tuned for nominal operation for acceptance of ions with initial energy of up to $\sim 25$ volts. Following this, a suitable voltage offset is applied to the sample high voltage, so that secondary ions with initial energies within a 25 volts band above the offset value will only reach the magnetic (mass-analyzer) sector of the instrument. We have adopted a value of 80 volts for this offset. The residual monoxide interferences still present at this 
offset voltage are corrected using appropriate data deconvolution procedure (see section 2.5).

\subsection{Mass-magnetic field calibration}

Measurements of REE and RTE abundances in a sample by ion microprobe involve determination of secondary ion intensities over a very broad mass interval starting with oxygen $(M=16 \mathrm{amu})$ and beyond the range of REE masses ( $M=180 \mathrm{amu})$. The measurement of ion intensities at different masses of interest is done in a peak-jumping mode by cycling the magnet through different field settings corresponding to the masses of interest. It is therefore essential to calibrate the magnetic field settings over the entire mass range prior to the start of an analysis. This is achieved by initially identifying mass peaks of silicon $\left({ }^{28} \mathrm{Si}\right)$ and its oxides (e.g., ${ }^{28} \mathrm{Si}^{16} \mathrm{O},{ }^{28} \mathrm{Si}_{2}{ }^{16} \mathrm{O},{ }^{28} \mathrm{Si}_{3}{ }^{16} \mathrm{O}_{4}$ etc) in a sample of pure Si-wafer, without any voltage offset. A typical calibration curve thus obtained is shown in figure 2. Special precautions are then taken to ensure a proper mass-magnetic field calibration in the REE region ( $M=136$ to $180 \mathrm{amu}$ ) by analyzing synthetic silicate glass standards doped with various REEs with concentrations of $\sim 500 \mathrm{ppm}$ (NIST standard; Fahey 1998) and $\sim 4 \%$ (Drake and Will 1972). Major element species present in these glasses ( $\mathrm{Ca}, \mathrm{Al}$ and $\mathrm{Si}$ ) may also be used for refining the mass-magnetic field calibration in the lower mass region. The procedure is then repeated using appropriate voltage offset. Several mass-scans in the REE mass region taken at a low mass resolution $(M / \Delta M \sim 270)$ and with a sample voltage offset of 80 volts following a masscalibration routine are shown in figure 3 . A proper mass-magnetic field calibration will result in these mass-spectra centered at the pre-calibrated values; this is clearly evident in this figure. We also show in this figure the typical mass-interval $\left(\Delta M_{s}\right)$ that is scanned to obtain ion intensities at these masses during REE analysis.

\subsection{Data acquisition and deconvolution}

A typical REE analysis involves measuring ion intensities in the following mass regions of interest; 16-30, 42-57, 86-94 and 138-180 (masses in amu). The nominal counting time at each mass is $\sim 30 \mathrm{~s}$ in the REE region $(138-180 \mathrm{amu})$ and $\leq 10 \mathrm{~s}$ in the other mass regions. To ensure stability, data acquisition at each mass starts following a short delay of $\sim 1 \mathrm{~s}$ after the magnetic field is adjusted by the software routine for that mass peak. An additional

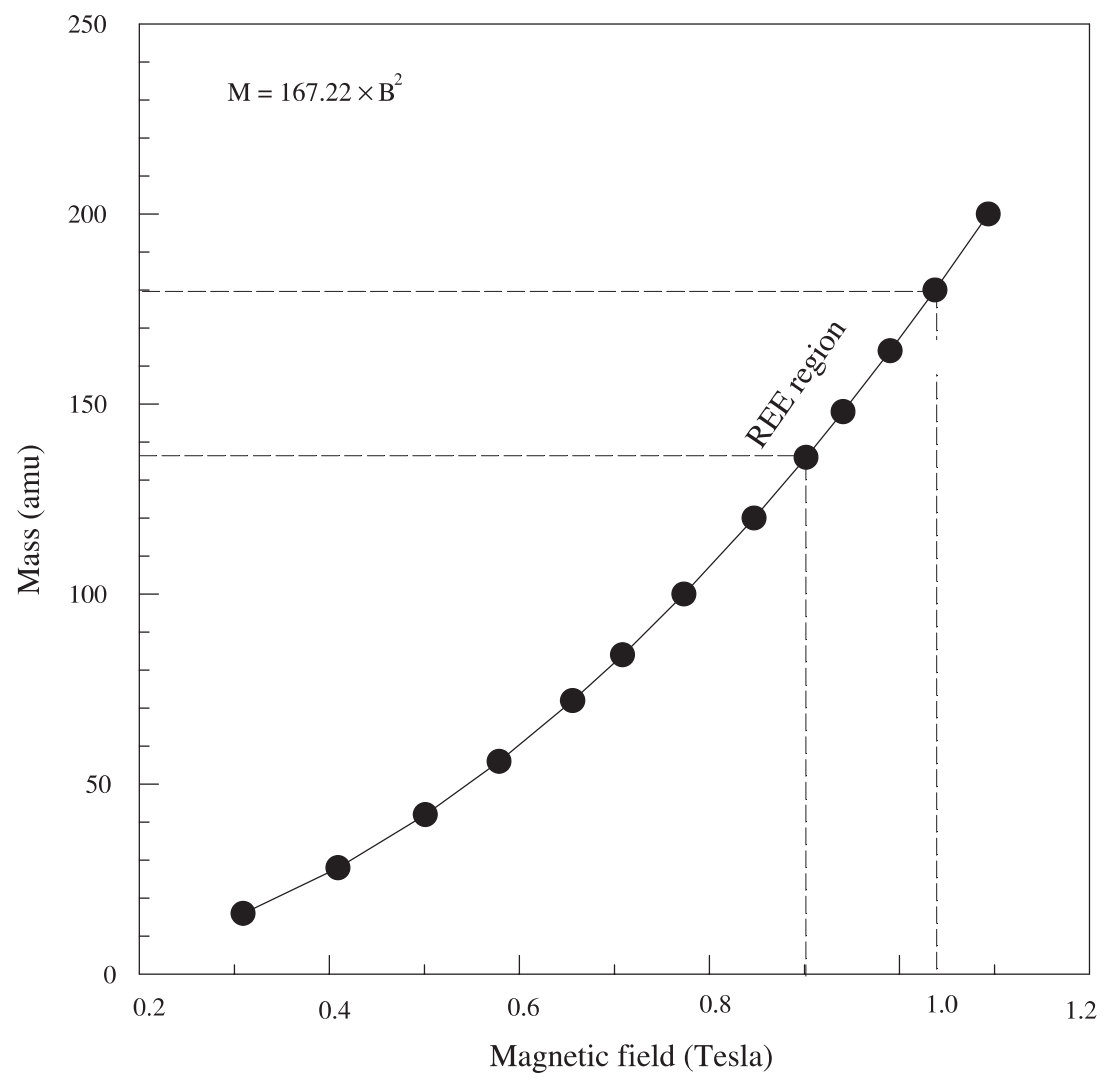

Figure 2. Mass-magnetic field calibration curve generated with the help of a silicon wafer using various elemental and molecular combinations of silicon and oxygen. The data points correspond to the various masses where the calibration was done. The mass region corresponding to the REEs is indicated. 
Mass Resolution $(\mathrm{M} / \Delta \mathrm{M})=270$; Energy Offset $=80$ volts
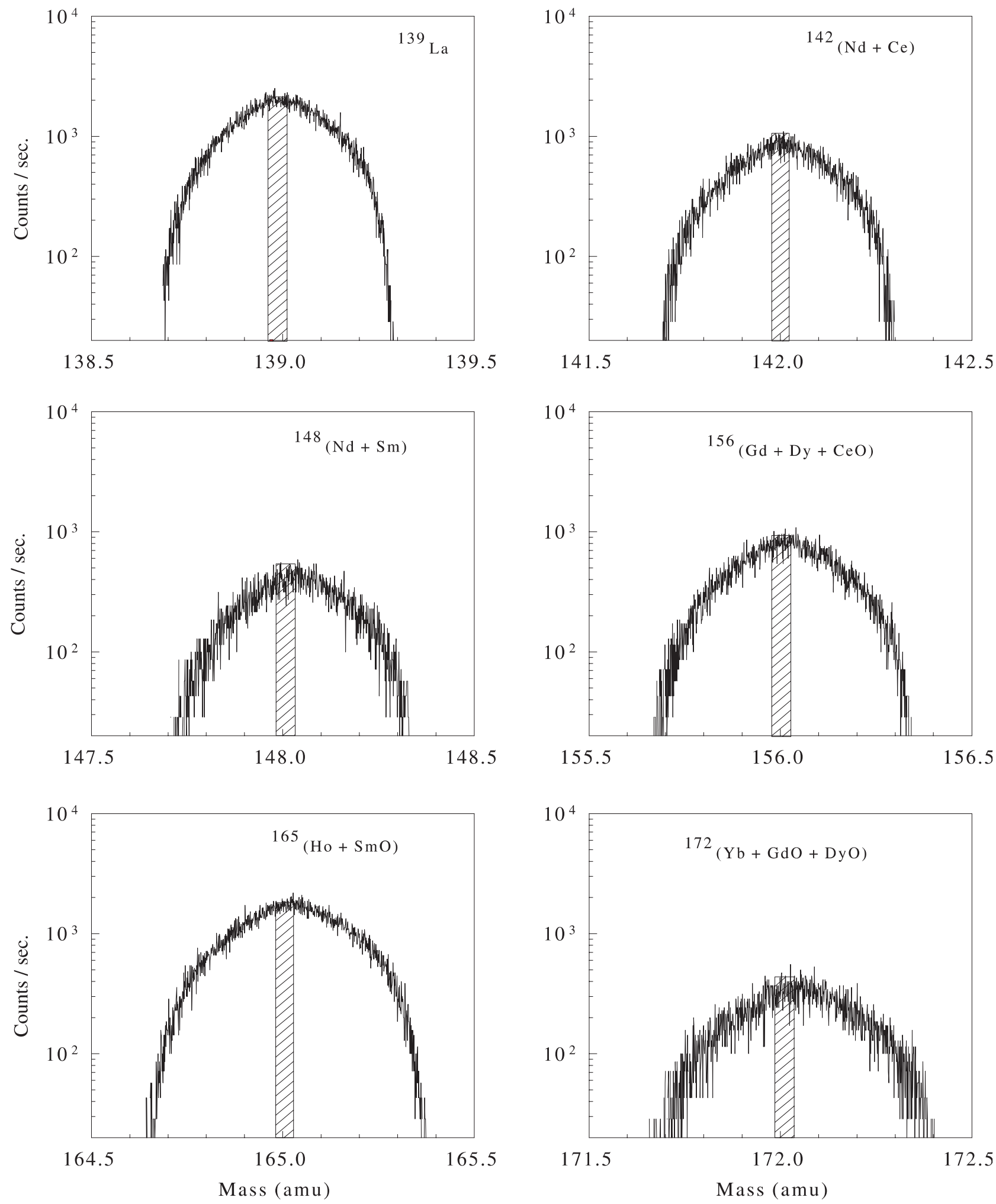

Figure 3. Mass spectra at some selected REE masses obtained at a low mass resolution $(M / \Delta M=270)$. The various isotopic and residual monoxide species that may contribute to the measured intensities at these masses are indicated. The hatched regions represent mass interval scanned $\left(\Delta M_{S}\right)$ during REE analysis. 
time delay $(\sim 5 \mathrm{~s})$ is also introduced when the magnetic field jumps from one mass region to another. The measurements are performed in an automated peak jumping/scanning mode and a single analysis lasts about 30 minutes. Repeat measurements are performed to improve statistical precision if the count rates at the REE masses are low; a massmagnetic field calibration for the REE region is executed before each measurement session.

The ion intensities at different masses in the low mass region $(M<94 \mathrm{amu})$ are ascribed to a particular isotope of a given element. However, in the REE region $(M=130-180 \mathrm{amu})$ the ion intensity at each of the masses could have contributions from one or more REE isotopes as well as from isobaric oxide (e.g., see figure 3). To obtain intensity of the REE ions of interest, we follow the procedure outlined by Fahey (1998) and frame a set of equations where ion intensity at each mass is equated to the sum of ion intensities due to one or more elemental (isotopic) species and residual isobaric monoxide species at that mass. This will constitute a set of 59 equations with 33 unknowns that correspond to abundances of the various REE isotopes and interfering monoxide species. A least square solution of this over-determined set of equations yield the REE ion intensities. Two sets of parameters, the ratios of ion intensities of REE-oxides and REEs and sensitivity factors for secondary ion yield of various
REEs are also needed to obtain the true REE ion intensities and convert them to REE abundances.

\subsection{Oxide to element ratios and sensitivity factors}

The data deconvolution procedure requires the ratio of ion intensities of $\mathrm{REE}$ oxide to REE (e.g., $[\mathrm{LaO}]^{+} / \mathrm{La}^{+},[\mathrm{CeO}]^{+} / \mathrm{Ce}^{+},[\mathrm{PrO}]^{+} / \mathrm{Pr}^{+}$etc), termed as oxide factors, as input parameters. These ratios are determined by using synthetic silicate glass standard doped with specific REEs such that they are free of oxide interferences from lower mass REEs. We have used the NIST standard K3399 for determining oxide factors for $\mathrm{La}, \mathrm{Ce}, \mathrm{Pr}, \mathrm{Nd}$, Sm and $\mathrm{Eu}$ and the NIST standard K3400 for Gd, Dy, $\mathrm{Tb}$ and Er. The measured oxide factors for different offset voltages are shown in figure 4 . The oxide to element ratio decreases with increasing offset voltage and one has to choose appropriate values based on the applied offset voltage during REE analysis.

The data deconvolution programme yields intensities of secondary REE ions sputtered from the analyzed samples. To convert the ion intensities to absolute REE abundances, we need to know the sensitivity factors for different REEs, i.e., the relative secondary ion yield of the REEs during sputtering of the sample surface. The sensitivity factors were determined by analyzing the NIST standard

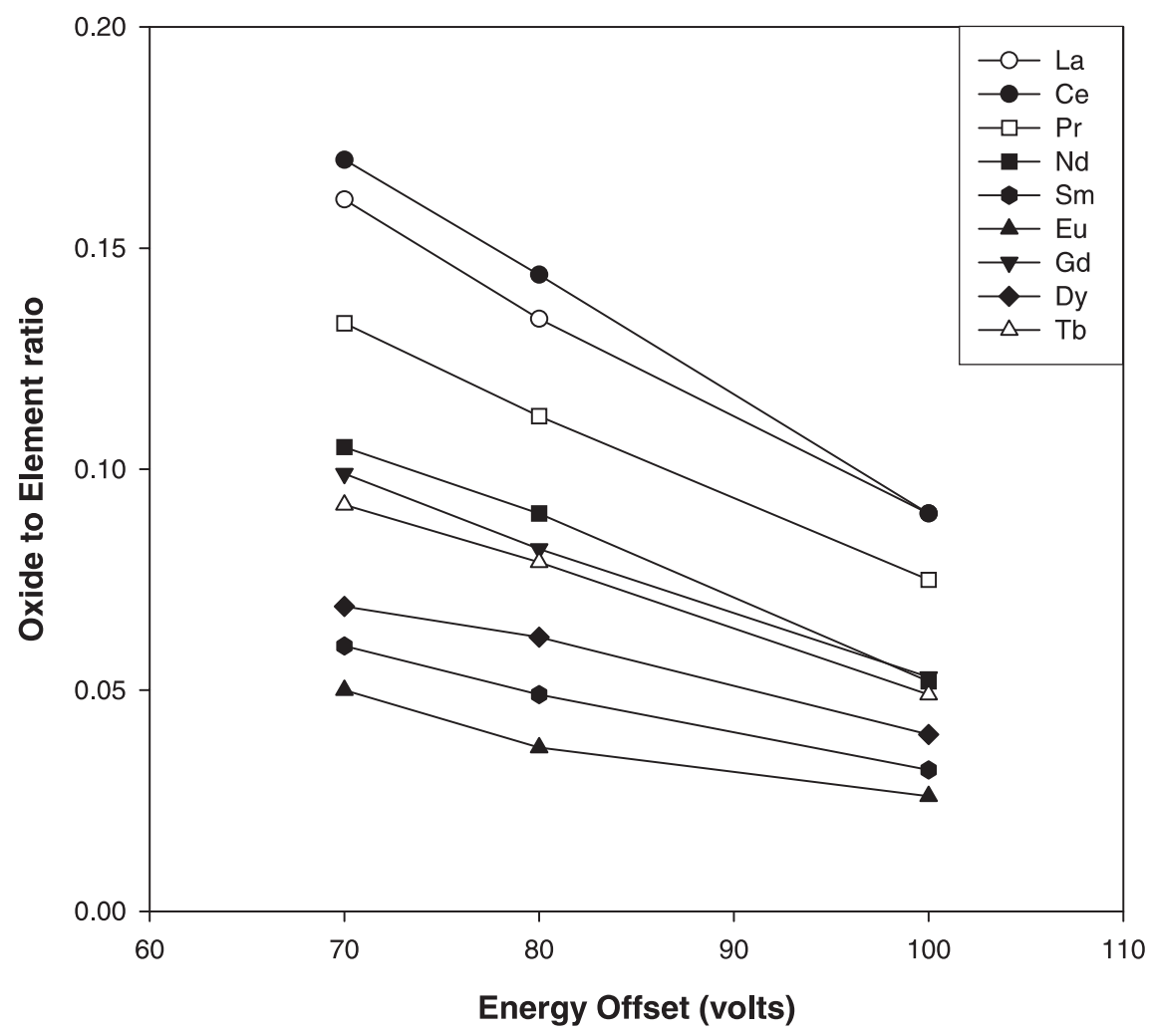

Figure 4. (REE-oxide $)^{+} /(\mathrm{REE})^{+}$ratios obtained experimentally for NIST silicate standards as a function of voltage offset. 


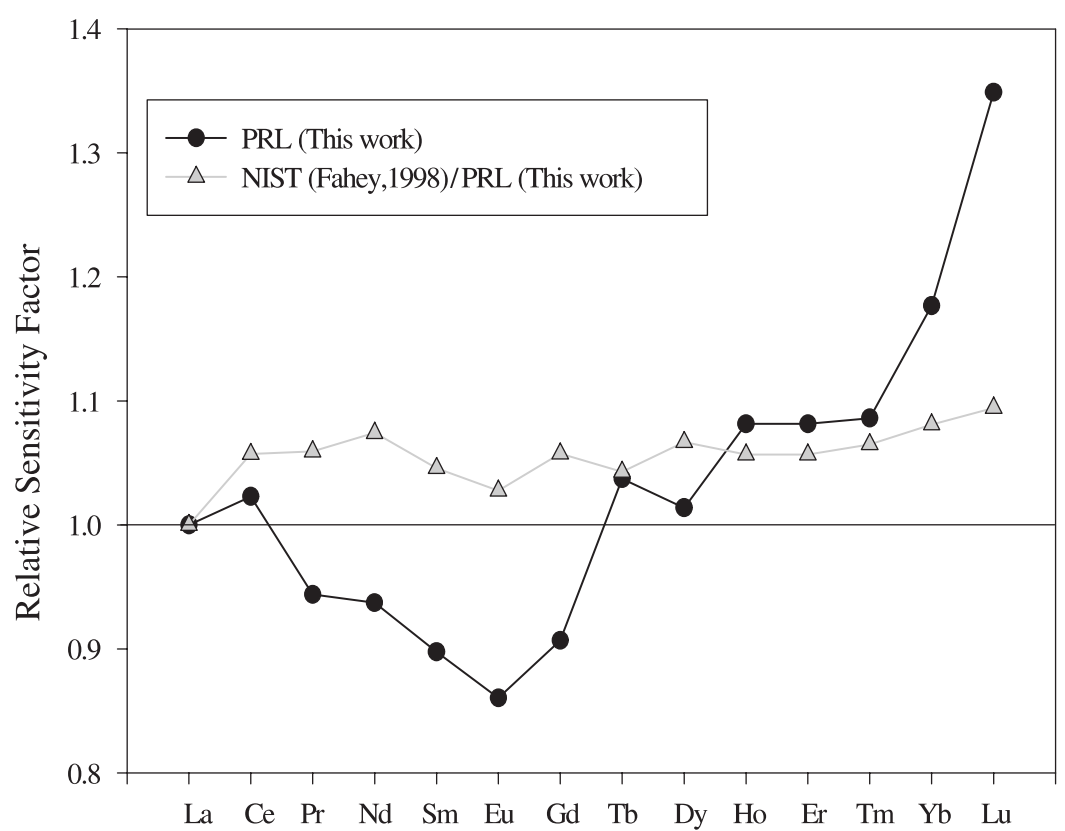

Figure 5. REE sensitivity factors (normalized to La) inferred from analyzing the silicate standard, SRM610. Also shown are the relative differences in sensitivity factors obtained by us and Fahey (1998) using similar ion microprobes (labeled NIST/PRL).

SRM 610 that has nominal concentration of $500 \mathrm{ppm}$ of all the REEs. A series of five to six analyses were done to obtain a mean value of the sensitivity factors using the relation:

Sensitivity factor

$$
=\frac{\left([\mathrm{REE}]_{\text {conc. }} /[\text { Ref. element }]_{\text {conc. }}\right)}{\left([\mathrm{REE}]^{+} /[\text {Ref. element }]^{+}\right)}
$$

The reference (Ref.) element may be $\mathrm{Si}\left({ }^{30} \mathrm{Si}^{+}\right)$, $\mathrm{Ca}\left({ }^{42} \mathrm{Ca}^{+}\right)$or other major elements chosen on the basis of the composition of the analyzed sample. The concentration of the reference element is obtained by electron microprobe. The sensitivity factors may be instrument specific and depend on the instrument settings, detector (electron multiplier) characteristics and are determined before each session of REE analysis. However, differences in relative sensitive factors reported by various laboratories are generally very small. For example, differences in relative REE sensitivities for the PRL and NIST instruments are $<10 \%$ (figure 5 ). The sensitivity factors also show some dependence on matrix composition and suitable standards should be used for obtaining appropriate sensitivity factors (see e.g., Fahey 1998).

We have developed a software package based on the singular value decomposition subroutine (Press et al 1993), for data deconvolution. However, the data reported here are based on a data deconvolution programme (courtesy A. Fahey) that is used in several ion probe laboratories (Fahey 1998). Both these approaches involve minimizing $\chi^{2}$ using matrix inversion and yield nearly identical results (see figure 6). The deconvolution is done in three iterative steps. In the first step, ion intensities of the elements $\mathrm{La}$ to $\mathrm{Eu}$ are obtained. Using these estimates and the data for the oxide to element ratios for these REEs, the ion intensities for Gd to Tm are obtained. Finally, using the oxide to element ratios of the second group of elements, the ion intensities of $\mathrm{Yb}, \mathrm{Lu}$, Hf are evaluated in the third iteration step. The REE ion intensities are then converted to REE abundances using the values of the relative sensitivity factors.

\section{Results and discussion}

\subsection{REE abundances in synthetic standards}

Following the optimization of all the experimental and analytical parameters, we have analyzed a set of NIST silicate glass standards to check the precision and reproducibility in determining REE abundances using the Cameca ims-4f ion microprobe at PRL. Test runs of the NIST standard SRM 610 that was used to infer the sensitivity factors of silicates, reproduce REE abundances to within $5 \%$ of their true values (figure 6a). Two other NIST standards (SRM612 and KW3610) were analyzed as unknowns and yielded REE abundances that are within 10 to $15 \%$ of their true values (figures $6 \mathrm{~b}$ and $6 \mathrm{c}$ ). The somewhat larger deviation from true values in these cases may be due to systematic uncertainties in both experimental and analytical procedures followed by us. Nonetheless, these 

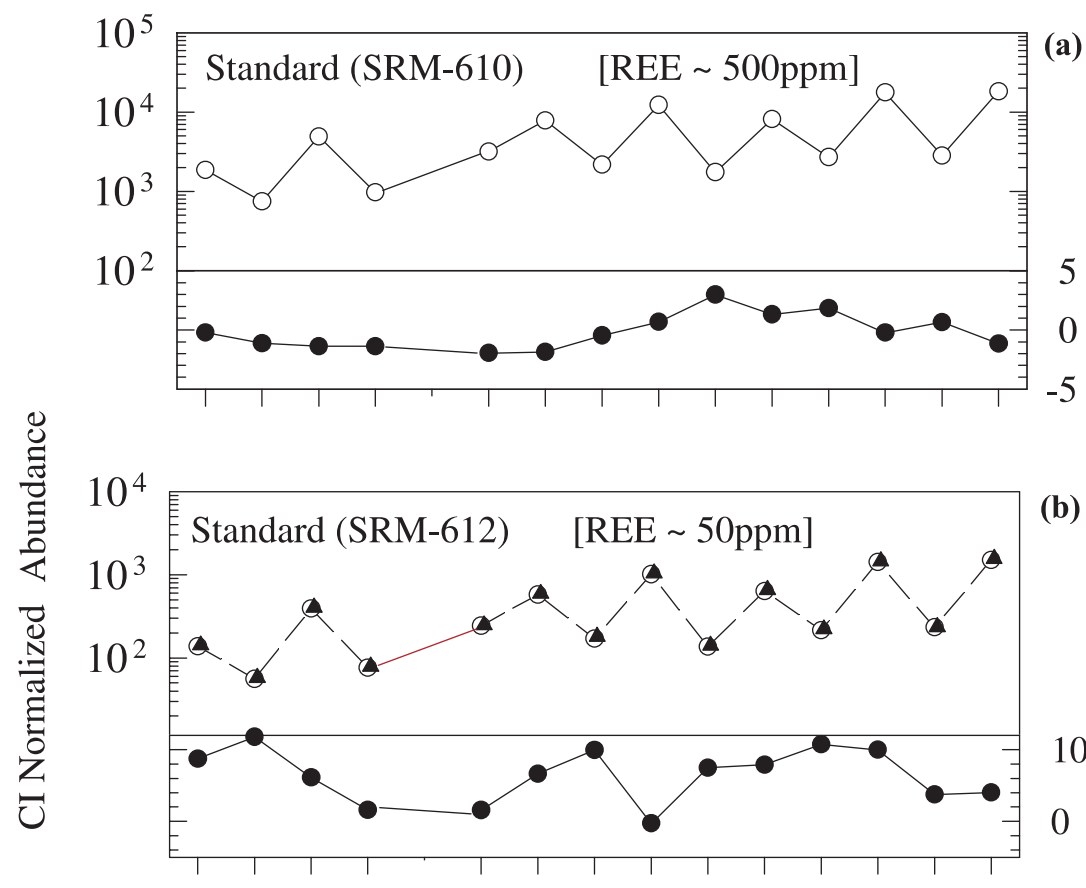

(b)

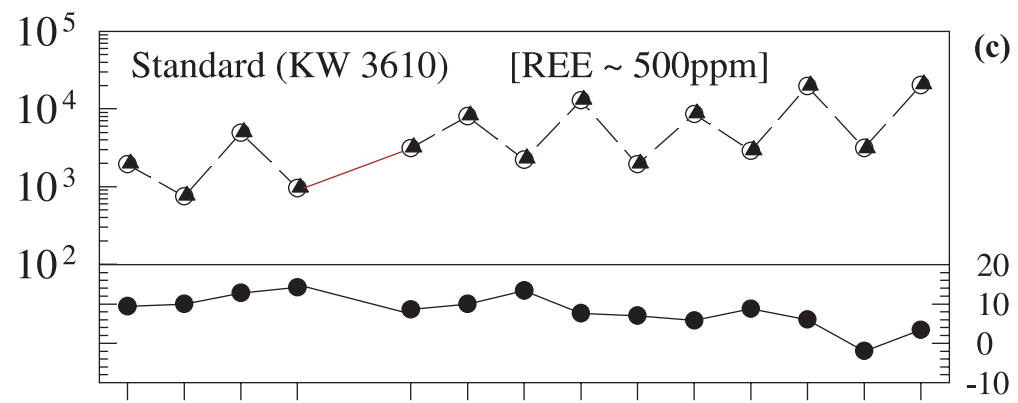

La Ce Pr Nd Sm Eu Gd Tb Dy Ho Er Tm Yb Lu

Figure 6. (a) CI normalized REE abundances in the silicate standard SRM610 (upper panel); the deviations from true abundances $(\sim 500 \mathrm{ppm})$ are $\leq 5 \%$ (lower panel scale on right). (b) CI normalized REE abundances in the silicate standard SRM612; the deviations from true abundances $(\sim 50 \mathrm{ppm})$ are $\leq 10 \%$. (c) CI normalized REE abundances of the silicate standard KW3610; the deviations from true abundances $(\sim 500 \mathrm{ppm})$ are $\leq 15 \%$. The REE abundances obtained by using the two data deconvolution programmes (see text), represented by the triangles and circles, respectively, are almost identical.

results show that the PRL ion microprobe may be used in a routine manner to determine REE abundance at tens of ppm level with an uncertainty of $\sim 10-15 \%$.

\subsection{REE and RTE abundance in early solar system objects}

We have determined abundances of REE and additional RTE such as Sr, Ba, Sc, Y, Zr, Nb, Hf and $\mathrm{V}$ in a rare refractory phase, hibonite $\left[\mathrm{Ca}, \mathrm{Al}_{12-X}(\mathrm{Mg}, \mathrm{Ti})_{X} \mathrm{O}_{19}\right]$, present in two primitive carbonaceous (CM) chondrites, Murchison and Murray. Hibonite has a condensation temperature of $\sim 1700 \mathrm{~K}$ and is considered to be one of the first solids to form in a high temperature solar nebula environment during the very early stages of evolution of our solar system (Yoneda and Grossman 1995). More than twenty hibonite belonging to two distinct morphological groups were recovered from these two CM meteorites. One group of hibonite occurs as individual platy crystal (platelet), while the other hibonites occur as elongated laths within spinel matrix in spheroid-shaped objects (spherules). The platelet hibonites are typically 50-60 micron across, while the hibonite laths in the spherule are a few tens of micron in length and 10 to 15 micron in width. Representative examples of the two groups of hibonites are shown in figure 7. A total of 15 hibonites, five belonging to the platelet group and ten belonging to the spherule group were analyzed for their REE and RTE abundances using the PRL ion microprobe. The absolute REE and RTE abundances are given in tables 1 and 2. The REE and RTE abundances in some selected hibonites, normalized to abundances 

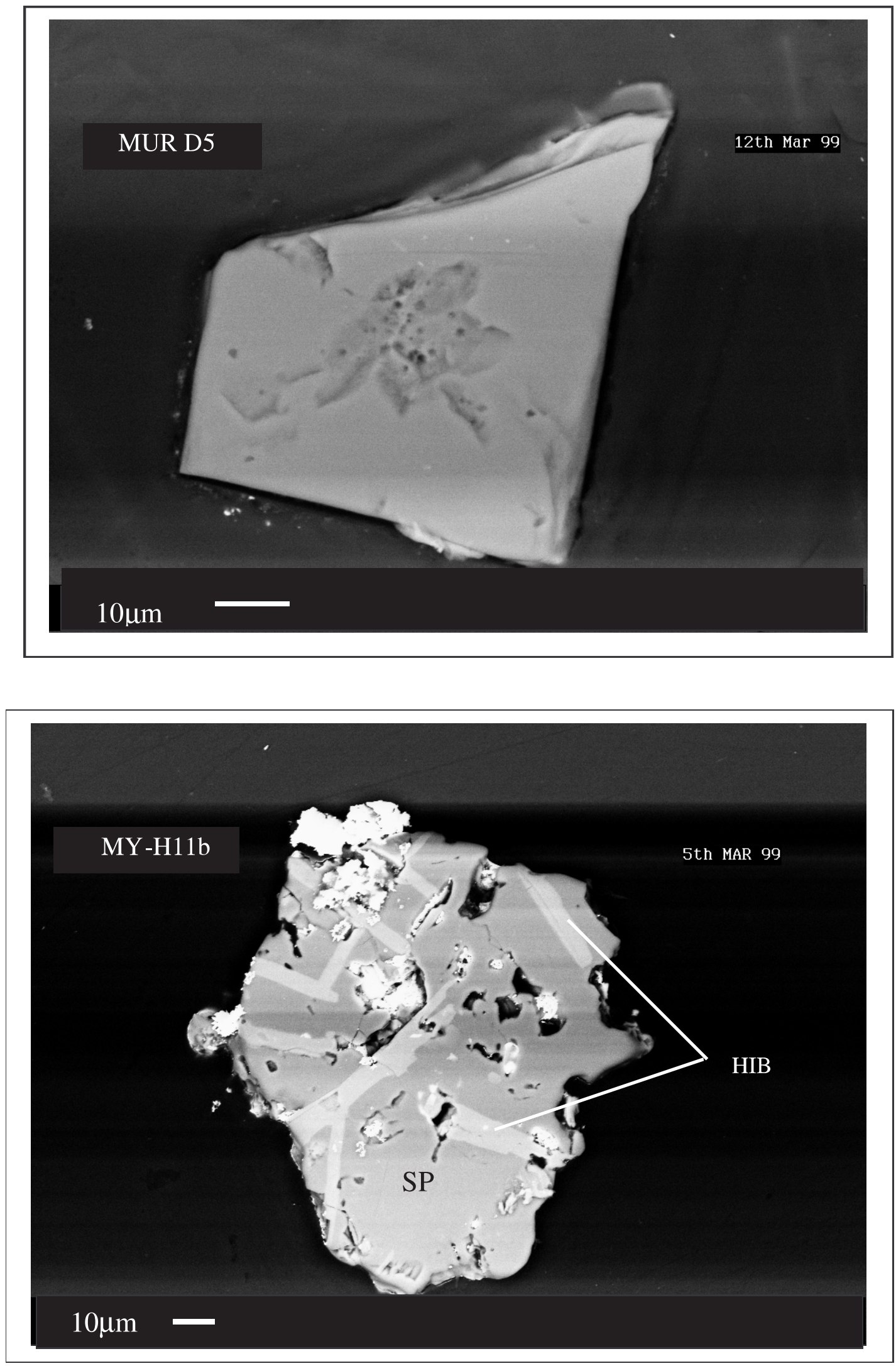

Figure 7. Backscattered electron images of hibonite from the Murchison (MUR) and Murray (MY) meteorites belonging to the two distinct morphologies, platelet (top photograph) and spherule (bottom photograph). The two major phases present in the spherule, hibonite (HIB) and spinel (SP), are labeled. 
Table 1. REE and RTE abundances (ppm) in platelet hibonites from CM chondrites.

\begin{tabular}{|c|c|c|c|c|c|}
\hline \multicolumn{5}{|c|}{ Murchison } & \multirow{2}{*}{$\begin{array}{l}\text { Murray } \\
\text { MY H17 }\end{array}$} \\
\hline & CH-B5 & $\mathrm{CH}$ C1 & $\mathrm{CH} \mathrm{C6}$ & CH D5 & \\
\hline $\mathrm{Sr}$ & $10.2 \pm 0.1$ & $75.1 \pm 0.5$ & $88.4 \pm 0.7$ & $75.8 \pm 0.7$ & $55.9 \pm 1.2$ \\
\hline $\mathrm{Ba}$ & $2.0 \pm 0.1$ & $6.0 \pm 0.2$ & $7.0 \pm 0.2$ & $5.2 \pm 0.2$ & $3.7 \pm 0.2$ \\
\hline$\overline{\mathrm{Sc}}$ & $76.7 \pm 0.1$ & $359.5 \pm 0.7$ & $351.0 \pm 0.7$ & $548.7 \pm 1.0$ & $140.3 \pm 1.1$ \\
\hline $\mathrm{Y}$ & $74.4 \pm 0.4$ & $106.3 \pm 0.7$ & $148.8 \pm 0.9$ & $573.7 \pm 2.0$ & $62.5 \pm 1.3$ \\
\hline$\overline{\mathrm{Zr}}$ & $164.8 \pm 0.8$ & $483.2 \pm 2.9$ & $551.5 \pm 3.5$ & $1568.2 \pm 6.4$ & $277.6 \pm 5.5$ \\
\hline $\mathrm{Nb}$ & $0.6 \pm 0.1$ & $0.2 \pm 0.1$ & $0.2 \pm 0.1$ & $1.0 \pm 0.1$ & $0.6 \pm 0.2$ \\
\hline$\overline{\mathrm{Hf}}$ & $98.5 \pm 9.9$ & $9.0 \pm 1.1$ & $6.6 \pm 1.2$ & $20.5 \pm 2.4$ & $4.2 \pm 1.4$ \\
\hline $\mathrm{V}$ & $0.7 \pm 0.01$ & $85.0 \pm 0.5$ & $90.6 \pm 0.6$ & $94.3 \pm 0.6$ & $197.4 \pm 1.8$ \\
\hline $\mathrm{La}$ & $100.1 \pm 1.8$ & $24.2 \pm 0.4$ & $24.5 \pm 0.5$ & $52.0 \pm 0.8$ & $26.7 \pm 0.7$ \\
\hline$\overline{\mathrm{Ce}}$ & $103.2 \pm 1.2$ & $57.9 \pm 0.7$ & $67.2 \pm 0.9$ & $125.3 \pm 1.4$ & $67.6 \pm 1.3$ \\
\hline$\overline{\mathrm{Pr}}$ & $91.4 \pm 2.6$ & $8.0 \pm 0.2$ & $8.5 \pm 0.3$ & $18.3 \pm 0.4$ & $8.7 \pm 0.4$ \\
\hline $\mathrm{Nd}$ & $97.5 \pm 1.2$ & $39.7 \pm 0.6$ & $40.1 \pm 0.6$ & $90.6 \pm 1.0$ & $43.7 \pm 1.0$ \\
\hline $\mathrm{Sm}$ & $93.6 \pm 2.9$ & $11.1 \pm 0.4$ & $10.8 \pm 0.4$ & $26.7 \pm 0.8$ & $16.1 \pm 0.9$ \\
\hline $\mathrm{Eu}$ & $18.5 \pm 1.5$ & $0.9 \pm 0.1$ & $1.0 \pm 0.1$ & $0.8 \pm 0.1$ & $0.9 \pm 0.1$ \\
\hline$\overline{\mathrm{Gd}}$ & $108.1 \pm 3.0$ & $13.4 \pm 0.5$ & $13.7 \pm 0.6$ & $37.7 \pm 1.1$ & $8.9 \pm 0.8$ \\
\hline $\mathrm{Tb}$ & $128.9 \pm 5.4$ & $3.5 \pm 0.2$ & $3.1 \pm 0.2$ & $8.3 \pm 0.4$ & $2.6 \pm 0.3$ \\
\hline Dy & $110.4 \pm 1.9$ & $17.4 \pm 0.4$ & $22.0 \pm 0.5$ & $51.4 \pm 0.8$ & $12.5 \pm 0.6$ \\
\hline Ho & $104.3 \pm 3.9$ & $3.5 \pm 0.2$ & $4.7 \pm 0.2$ & $10.4 \pm 0.4$ & $2.7 \pm 0.3$ \\
\hline Er & $78.9 \pm 2.1$ & $6.4 \pm 0.3$ & $10.3 \pm 0.4$ & $22.5 \pm 0.6$ & $4.4 \pm 0.4$ \\
\hline $\mathrm{Tm}$ & $46.9 \pm 4.0$ & $0.5 \pm 0.1$ & $1.1 \pm 0.1$ & $1.6 \pm 0.2$ & $0.5 \pm 0.1$ \\
\hline $\mathrm{Yb}$ & $2.6 \pm 1.1$ & $0.1 \pm 0.1$ & $0.06 \pm 0.2$ & $0.8 \pm 0.3$ & $0.7 \pm 0.3$ \\
\hline $\mathrm{Lu}$ & $29.4 \pm 4.7$ & $0.3 \pm 0.1$ & $1.0 \pm 0.1$ & $2.8 \pm 0.3$ & $0.0 \pm 0.1$ \\
\hline
\end{tabular}

in carbonaceous (CI) chondrites are shown in figure 8.

REE abundances in refractory early solar system solids generally reveal several distinct patterns (Martin and Mason 1974; MacPherson et al 1988). The measured REE abundances in most of the hibonites closely resemble two of these patterns, Group II and Group III, with some variations. The platelet hibonites follow the Group III pattern characterized by nearly hundred-fold or more excess in the abundances of refractory REE relative to chondritic (CI) abundances with relative depletion in $\mathrm{Eu}$ and $\mathrm{Yb}$ (figure 8a). The depletion in $\mathrm{Eu}$ is lower than in $\mathrm{Yb}$ with $\mathrm{Eu} / \mathrm{Eu}^{*} \sim 0.1$ to 0.3 and $\mathrm{Yb} / \mathrm{Yb}^{*} \sim 0.01$ to 0.05 . The abundances of the RTE in the platelet hibonite also follow a similar trend with enhancement in the more refractory element ( $\mathrm{Sc}, \mathrm{Zr}$ and $\mathrm{Hf}$ ) and relative depletion in the less refractory elements, $\mathrm{Ba}, \mathrm{Nb}, \mathrm{V}$. Our results are in agreement with REE data for platelet hibonite reported earlier (Fahey et al 1987; Ireland et al 1988; Ireland 1990). The higher depletion of $\mathrm{Yb}$ relative to $\mathrm{Eu}$ was initially attributed to a late reequilibration in a reducing environment that led to addition of $\mathrm{Eu}$ as $\mathrm{Eu}^{2+}$, substituting for $\mathrm{Ca}^{2+}$
(Ekambaram et al 1984). However, Ireland et al (1988) argued that the absence of a similar signature for $\mathrm{Ce}$ (which behaves like $\mathrm{Eu}$ in a reducing condition) makes this proposal untenable and this difference may represent a primary signature of the initial reservoir. The Group III REE pattern seen in platelet hibonites is expected when REE abundances are governed by their relative volatility as is the case of formation of solids via condensation. Thus, the platelet hibonites could be probable high temperature solar nebula condensates, representing some of the earliest solar system solids. The possibility of these objects being refractory residues following incomplete volatilization of precursor nebular solids that removed the more volatile species was also suggested (Ireland 1990). Most of the platelet hibonite also show a smooth roll over in their heavy REE (HREE) abundances. This fractionation trend is suggestive of an igneous overprint and indicates that these platelets or their precursors have experienced some degree of partial melting and recrystallization.

The hibonite in spherules show a variety of fractionated REE patterns. Many of them show moderately fractionated light REE, a fractionated HREE 


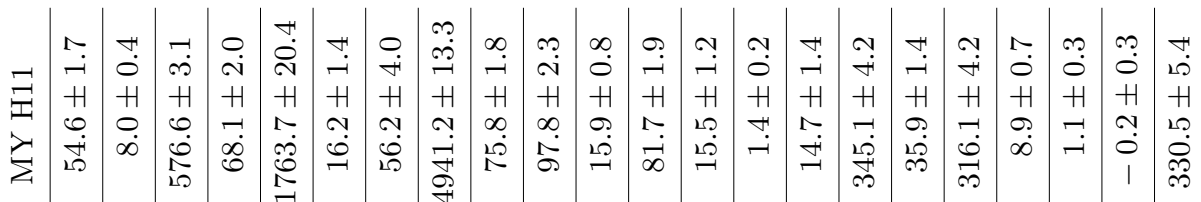

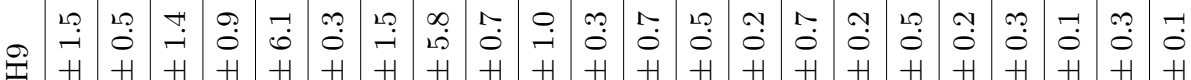
H H H H H H H H H H H H H H H H H H H H H H H

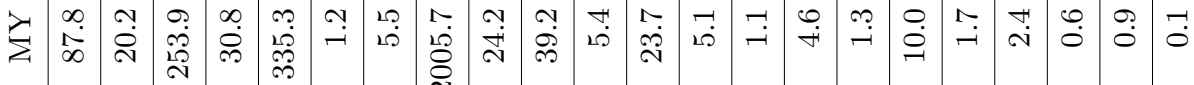

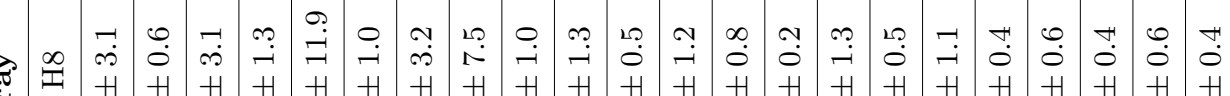

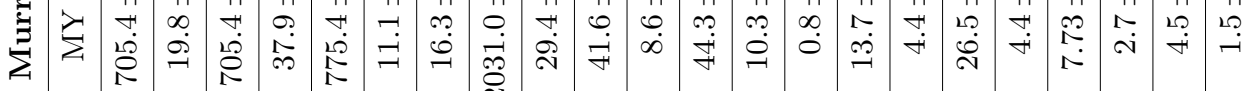

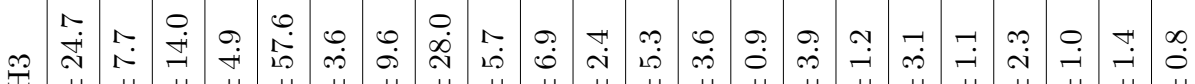

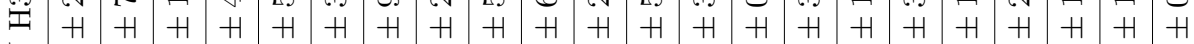

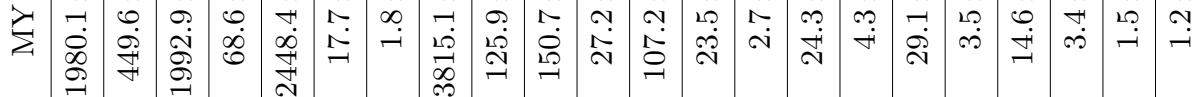

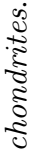

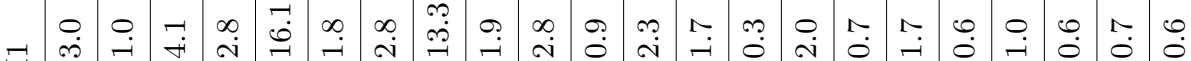

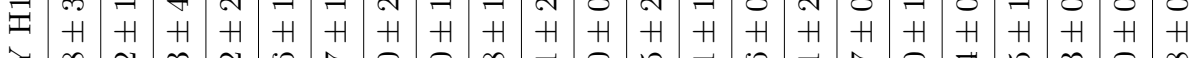

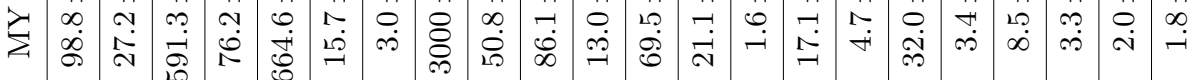

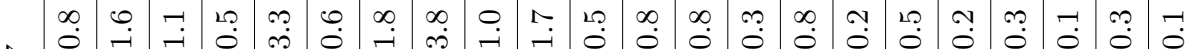

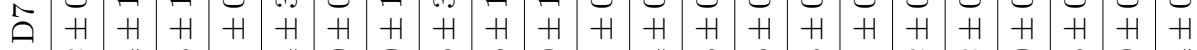

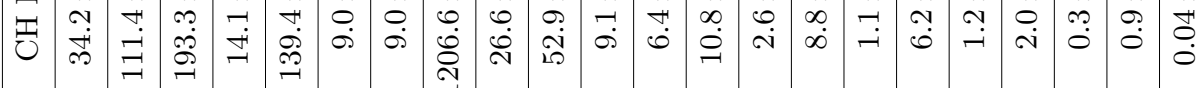

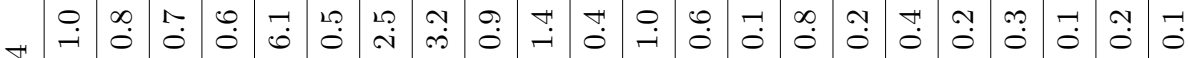

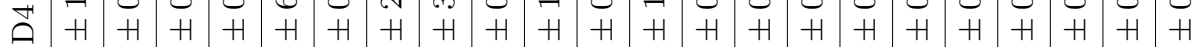

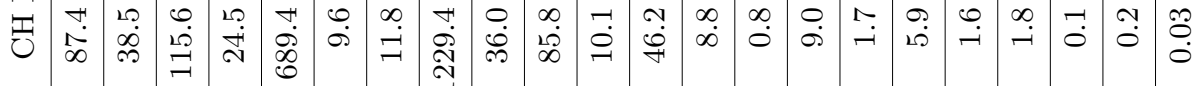

\section{西}

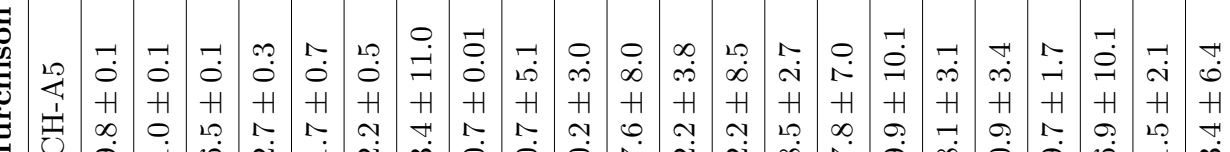

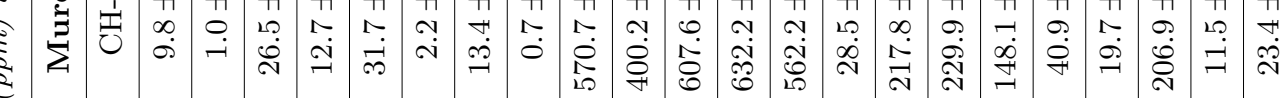

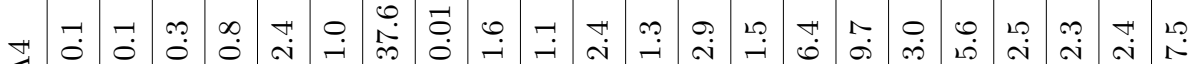
H H H H H H H H H H H H H H H H H H H H H H

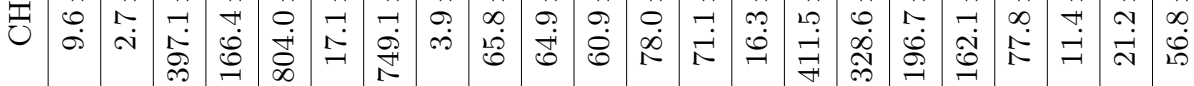

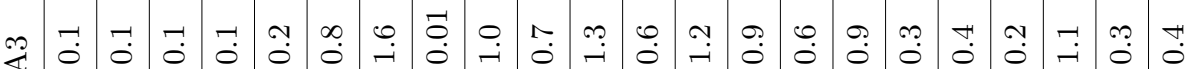
0
1
$H$

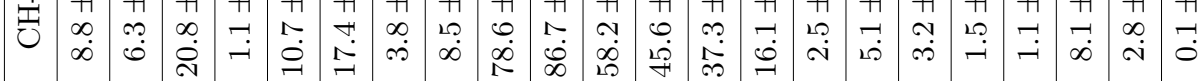
i $\frac{\sqrt{0}}{\frac{\pi}{0}}$

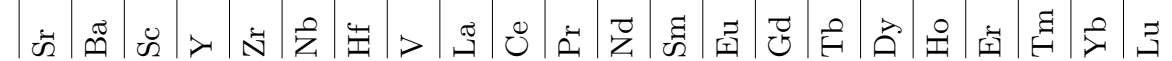


(a)
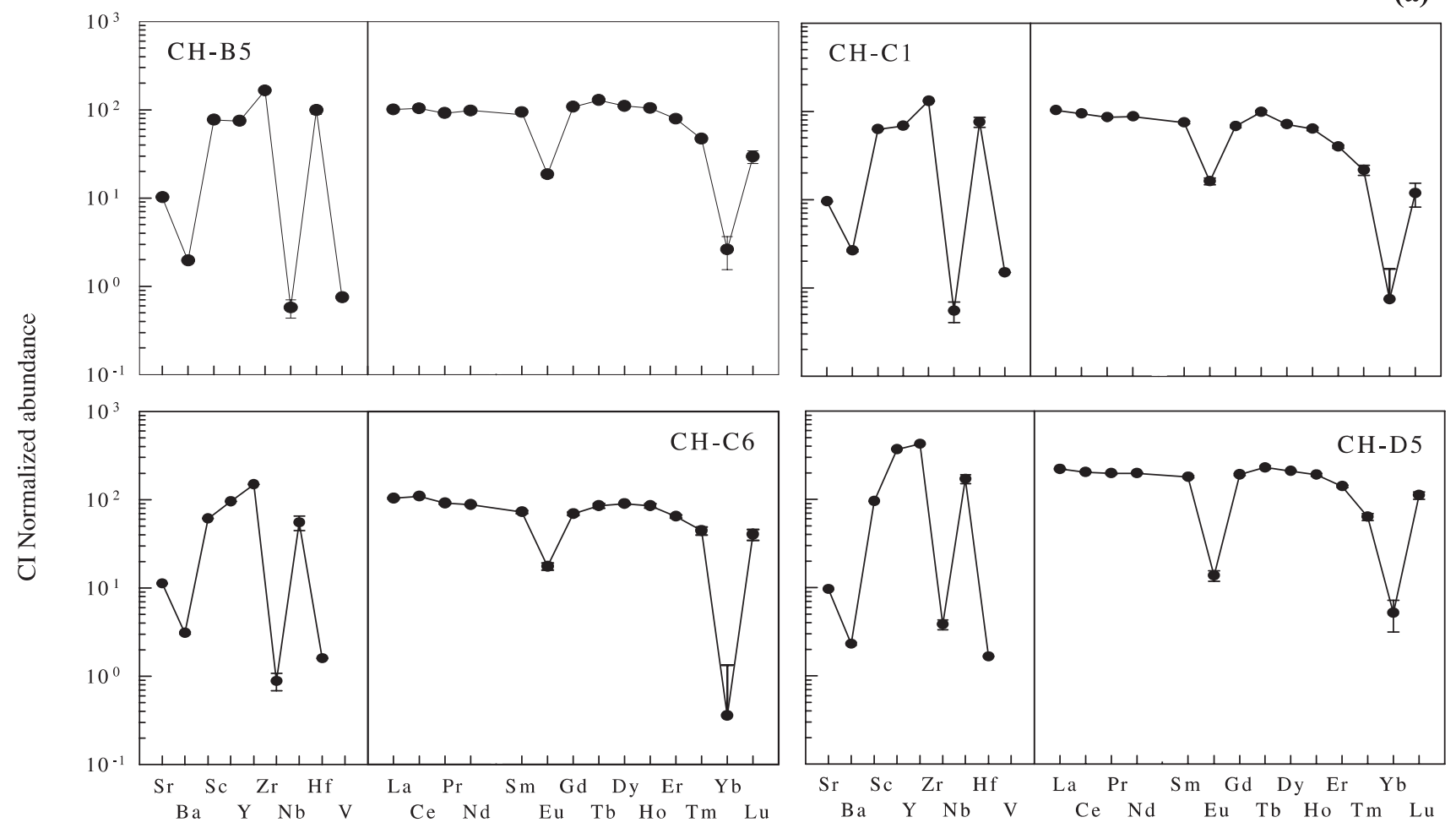

(b)
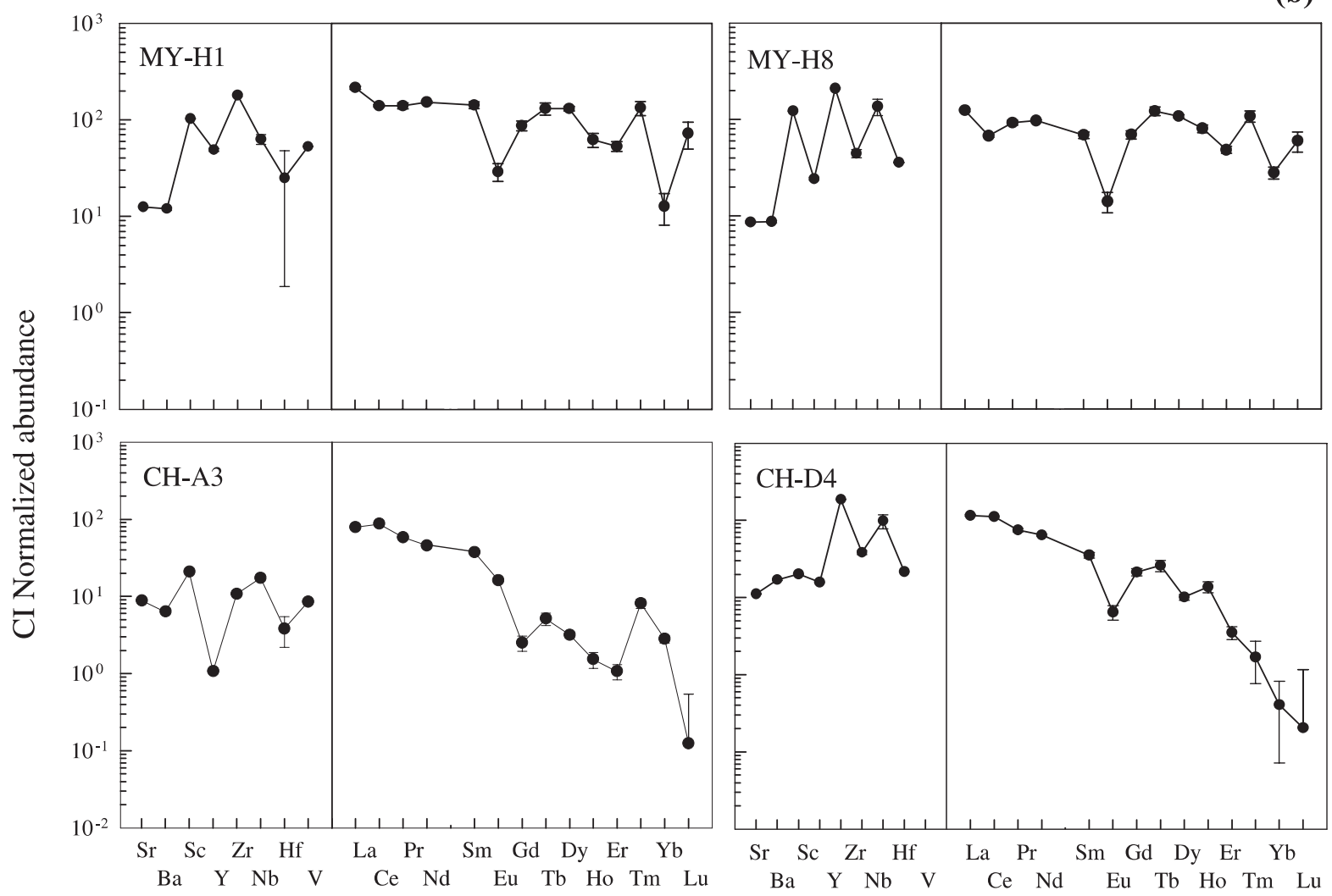

Figure 8. (Continued)

pattern, depletion in $\mathrm{Eu}$ and relative enrichment in Tm (figure 8b), features that are characteristics of the Group II REE pattern (Mason and Martin 1977). Such a pattern is expected if these objects or their precursors formed in a localized region of the solar nebula from which the ultra refractory REEs are already removed (Boynton 1975, 1989; Davis and Grossman 1979). Supportive evidence 


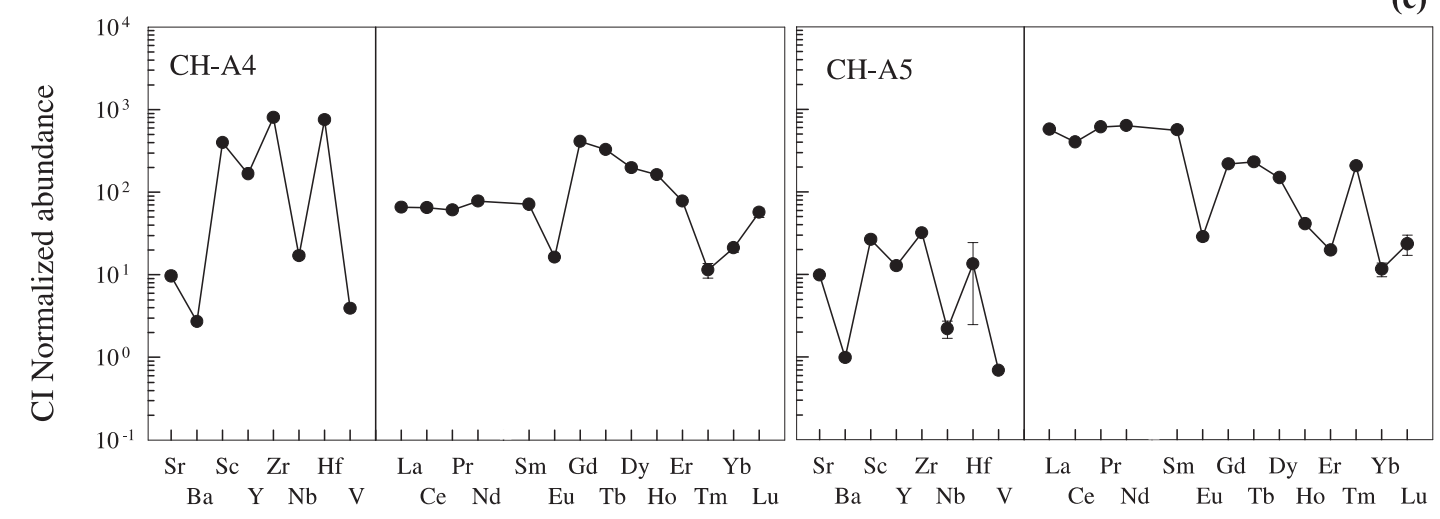

Figure 8. CI normalized REE and RTE abundances in a set of platelet hibonites (a), a set of hibonites present within refractory spinel-hibonite spherules (b), and in two hibonites in spherules with very distinct REE patterns (c); (note change in scale).

for this suggestion comes from the observation of complimentary ultra refractory REE pattern in some early solar system objects such as sample CH-A4 (figure 8c) in this study as well as in several previous studies (Boynton et al 1980; Ekambaram et al 1984; Hinton et al 1988; Ireland 1990). Hibonite in a few of the analyzed spherules display fractionated REE patterns that deviate from the typical Group II pattern. For example, hibonite in spherule $\mathrm{CH}-\mathrm{A} 3$ does not show strong depletion in $\mathrm{Eu}$ and $\mathrm{Yb}$, while hibonite in spherule $\mathrm{CH}-\mathrm{D} 4$ displays a smoothly decreasing REE pattern along with depletion in $\mathrm{Eu}$ (figure 8b). In general, the REE patterns for hibonites in most of the spherules indicate an igneous imprint and suggest them to be products of melting and recrystallization of precursor nebular solids in a high temperature environment. The variations in REE patterns seen in some of these objects also suggest that they could have experienced multiple episodes of melting and recrystallization (see e.g., Ireland et al 1988).

A couple of the analyzed hibonites belonging to the spherule group have distinctly different REE patterns (figure 8c). As already noted, hibonite in Murchison spherule $\mathrm{CH}-\mathrm{A} 4$ shows an ultrarefractory pattern superimposed with fractionated HREE. The enrichment of the refractory trace elements $\mathrm{Sc}, \mathrm{Zr}$ and $\mathrm{Hf}$ is also very high, a factor of $>500$ compared to CI abundances. On the other hand, hibonite in the Murchison spherule $\mathrm{CH}-\mathrm{A} 5$ exhibit a typical Group-II pattern for the heavy REE but show much higher enrichment in light REE. Further, unlike other hibonites of this group, it is depleted in the relatively volatile trace elements, $\mathrm{Ba}, \mathrm{Nb}$ and $\mathrm{V}$, but enriched in the refractory elements, Sc, Zr and Hf, a feature characteristic of the platelet group. Presence of hibonite in spherules with REE characteristics closer to the platelet (Group III pattern) was also noted in an earlier study (Ireland et al 1988). In contrast, presence of platelet hibonite with REE pattern resembling those of hibonite in spherules is yet to be reported and appears to be extremely rare. Even though the platelet hibonites and the spinelhibonite spherules appear to be two distinct groups of objects, their REE and RTE abundances suggest that they may represent a continuum of objects formed in specific nebular settings. It is probable that the formation of the platelet hibonites, that have signatures of being high temperature nebular condensates, and some of the other hibonites with ultrarefractory REE pattern took place in the solar nebula prior to the formation of the hibonite-bearing spherules with Group II REE pattern that are considered to be products of melting and recrystallization of precursor nebular solids in a high temperature environment. Isotopic studies of these two groups of objects tend to support this possibility (Sahijpal et al 2000).

\section{Conclusions}

Procedures adopted for implementing the "energyfiltering" technique for determination of REE and RTE abundances in terrestrial and extraterrestrial samples using the ion microprobe at PRL are described. Analysis of synthetic standards doped with varying amounts of REE show that REE abundances at ppm level can be measured routinely by the PRL ion microprobe with an uncertainty of 10-15\%. REE and RTE abundances measured in a set of microscopic early solar system objects representing some of the first solids to form in the solar nebula allowed delineation of the plausible processes leading to their formation in the nascent solar nebula.

\section{References}

Allegre C J, Prinzhofer A and Pierre A 1989 LIDIA: large isotope dilution ion-probe analyses; Earth Planet. Sci. Lett. 92 179-188 
Boynton W V 1975 Fractionation in the solar nebula: Condensation of yttrium and the rare earth elements; Geochim. Cosmochim. Acta 39 569-584

Boynton W V 1984 Cosmochemistry of the rare earth elements: Meteorite studies. In: Rare Earth Element Geochemistry (ed) P Henderson (Elsevier) pp 63-108

Boynton W V 1989 Cosmochemistry of the rare earth elements: Condensation and evaporation processes; Geochemistry and Mineralogy of Rare Earth Elements. (eds) B R Lipin, \& G A Mckay, Publication of Mineralogical Society of America, pp 1-24

Boynton W V, Frazier R M and Macdougall J D 1980 Identification of an ultra-refractory component in the Murchison meteorite (abstract); Lunar Planet. Sci. XI 103-105

Davis A M and Grossman L 1979 Condensation and fractionation of rare earths in the solar nebula; Geochim. Cosmochim. Acta 43 1611-1632

Drake M J and Weill D F 1972 New rare earth element standards for electron microprobe analysis; Chem. Geol. 10 179-181

Ekambaram V, Kawabe I, Tanaka T, Davis A M and Grossman L 1984 Chemical composition of refractory inclusions in the Murchison C2 chondrite; Geochim. Cosmochim. Acta 48 2089-2105

Fahey A J, Goswami J N, McKeegan K D and Zinner E $\mathrm{K} 1987{ }^{26} \mathrm{Al},{ }^{244} \mathrm{Pu},{ }^{50} \mathrm{Ti}, \mathrm{REE}$, and trace element abundances in hibonite grains from $\mathrm{CM}$ and $\mathrm{CV}$ meteorites. Geochim. Cosmochim. Acta 51 329-350

Fahey A J 1998 Details of the measurement of rare earth and other trace element abundances by secondary ion mass spectrometry; Int. J. Mass Spectrom. Ion Processes 176 63-76

Henderson P 1984 General geochemical properties and abundances of the rare earth elements. In: Rare Earth Element Geochemistry (ed) P Henderson (Elsevier) pp 1-29
Hinton R W, Davis A M, Scatena-Wachel D E, Grossman L and Draus R J 1988 A chemical and isotopic study of hibonite-rich refractory inclusions in primitive meteorites; Geochim. Cosmochim. Acta 52 2573-2598

Ireland T R 1990 Presolar isotopic and chemical signatures in hibonite-bearing refractory inclusions from the Murchison carbonaceous chondrite; Geochim. Cosmochim. Acta 54 3219-3237

Ireland T R, Fahey A J and Zinner E K 1988 Traceelement abundances in hibonites from the Murchison carbonaceous chondrite: constraints on high-temperature processes in the solar nebula; Geochim. Cosmochim. Acta 52 2841-2854

MacPherson G J, Wark D A and Armstrong J T 1988 Primitive material surviving in chondrites: Refractory inclusions. In: Meteorites and the early solar system (eds) J F Kerridge and M S Matthews (Univ. Arizona Press) pp 746-807

Martin P M and Mason B 1974 Major and trace elements in the Allende meteorite; Nature 249 333-334

Mason B and Martin P M 1977 Minor trace element distribution in melilite and pyroxene from the Allende meteorite; Earth Planet. Sci. Lett. 22 141-144

Press W H, Teukolsky S A, Vetterling W T and Flannery B P 1993 In: Numerical recipes in Fortran: The art of scientific computing (Cambridge University Press) pp 963

Sahijpal S, Goswami J N and Davis A M 2000 K, Mg, Ca and $\mathrm{Ti}$ isotopic compositions and refractory trace element compositions of hibonites from CV and CM meteorites; Geochim. Cosmochim. Acta 64 1989-2005

Yoneda S and Grossman L 1995 Condensation of CaO$\mathrm{MgO}-\mathrm{Al} \mathrm{O}-\mathrm{Si} \mathrm{O}$ liquids from cosmic gases. Geochim. Cosmochim. Acta 59 3413-3444

Zinner E and Crozaz G 1986 A method for the quantitative measurement of rare earth elements in the ion microprobe; Int. J. Mass Spectrom. Ion Processes 69 17-38 